\title{
Sudden commencement event of 17 April 2002: Aspects of the geomagnetic response at low latitudes
}

\author{
U. Villante, M. Piersanti, P. Di Giuseppe, and M. Vellante \\ Dipartimento di Fisica, Università ed Area di Astrogeofisica, L'Aquila, Italy
}

T. L. Zhang and W. Magnes

Space Research Institute, Austrian Academy of Science, Graz, Austria

Received 14 December 2004; revised 8 June 2005; accepted 22 June 2005; published 13 December 2005.

[1] An analysis of a sudden commencement (SC) manifestation reveals a significant contribution of the polar current system which influences the long-term behavior of the $\mathrm{H}$ component at low-latitude ground stations located in the subsolar sector. A transition between "morning" and "afternoon" characteristics of the geomagnetic response occurs at $\approx 1300$ MLT. "Morning" events are characterized by a positive then negative variation $(\mathrm{P} / \mathrm{N})$ preceding the longer-term variation and show a gentle latitudinal decrease of the asymptotic response; conversely, "afternoon" events, which are characterized by a N/P structure, show a steep latitudinal gradient. PPI and PRI structures are observed on opposite sides of the $\approx 1300$ MLT boundary. The PPI consists of three dominant fluctuations at well-defined frequencies and the small differences in the signal manifestation at nearby stations can be imputed to the occurrence of local resonance phenomena. Large-amplitude pulsations appear soon after the SC occurrence at subauroral latitudes.

Citation: Villante, U., M. Piersanti, P. Di Giuseppe, M. Vellante, T. L. Zhang, and W. Magnes (2005), Sudden commencement event of 17 April 2002: Aspects of the geomagnetic response at low latitudes, J. Geophys. Res., 110, A12S23, doi:10.1029/2004JA010978.

\section{Introduction}

[2] An interesting aspect of the relationships occurring between the solar wind (SW) and the Earth's magnetosphere is represented by the geomagnetic response to variations of the SW parameters. Indeed, the Earth's arrival of SW discontinuities characterized by sudden variations of the dynamic pressure $\left(\mathrm{P}_{\mathrm{sw}}\right)$, is related to impulsive variations of the geomagnetic field (sudden impulses, SIs, or storm sudden commencements, SSCs, with similar characteristics; hereafter SCs). SCs are classified as sharp variations of the north/south component $(\mathrm{H})$, with rise times which typically range between 1 and $9 \mathrm{~min}$; their amplitude is roughly proportional to $\mathrm{D}\left(\mathrm{P}_{\mathrm{sw}}^{1 / 2}\right)$. In addition, peak ("overshoot") values often precede a new steady state, which is typically referred as "asymptotic response" and shows an explicit longitudinal and latitudinal dependence [Siscoe et al., 1968; Su and Konradi, 1975; Nishida, 1978; Russell et al., 1992, 1994a, 1994b; Araki, 1994; Russell and Ginskey, 1995; Francia et al., 2001; Villante and Di Giuseppe, 2004].

[3] On the other hand, since early investigations [Matsushita, 1962; Nishida and Jacobs, 1962] it is well known that different transient waveforms of the $\mathrm{H}$ component are detected at different stations. According to Araki [1994], at auroral latitudes the $\mathrm{H}$ waveform typically con-

Copyright 2005 by the American Geophysical Union. 0148-0227/05/2004JA010978\$09.00 sists of two successive pulses with opposite sense (PI and MI, with typical duration of $\approx 1-2 \mathrm{~min}$ and $\approx 5-10 \mathrm{~min}$, respectively). In the morning a positive pulse precedes and a negative pulse follows. The sense of the pulses is reversed in the afternoon and their amplitude decreases with decreasing latitude. The $\mathrm{H}$ behavior becomes more step-like at middle and low latitudes, but a two pulse structure with reduced amplitude is still identified. At dayside equator the waveform is similar to that in the high-latitude afternoon sector with a preceding negative impulse (often identified as "preliminary reverse impulse," PRI, with a timescale of less than $1 \mathrm{~min}$ ), which rarely appears at low latitudes. Nowadays, the current understanding suggests a complex scenario which relates the $\mathrm{H}$ waveforms to the combined effects of the magnetopause and ionospheric current systems; namely, the total disturbance field $\left(\mathrm{D}_{\mathrm{SC}}\right)$ of the $\mathrm{H}$ component can be decomposed in different subfields [Araki, 1977, 1994; Araki et al., 1997]:

$$
\mathrm{D}_{\mathrm{SC}}=\mathrm{DL}+\mathrm{DP}_{\mathrm{PI}}+\mathrm{DP}_{\mathrm{MI}}+\mathrm{P}_{\mathrm{SC}} .
$$

According to models, the direct effect of the increased magnetopause current propagates to low and middle latitudes as a compressive wave and produces a step-like increase of the $\mathrm{H}$ component (DL field, where L stands for low latitudes); its amplitude is largest at the equator and decreases with increasing latitude. A dusk-to-dawn electric field along the compressional wave front induces a twin ionospheric vortex system that produces a preliminary 
impulse of polar origin $\left(\mathrm{DP}_{\mathrm{PI}}\right)$. On the other hand, if the increased pressure behind the SW discontinuity is kept up, the magnetospheric convection has to adjust itself to the compressed state of the magnetosphere: as a final result it produces a twin polar vortex system $\left(\mathrm{DP}_{\mathrm{MI}}\right)$ which is opposite to the $\mathrm{DP}_{\mathrm{PI}}$ field and corresponds to the MI. Such $\mathrm{DP}_{\mathrm{MI}}$ field is basically driven by an electric field originated in the polar region and transmitted from the outer magnetosphere through field-aligned current (FAC), which flow into the ionosphere in the morningside and away in the afternoonside. As matter of fact, $\mathrm{DP}_{\mathrm{PI}}$ and $\mathrm{DP}_{\mathrm{MI}}$ are often unified in a global DP field (where $\mathrm{P}$ identifies the polar origin). However, the preliminary impulse is exclusively due to current systems of polar origin, $\mathrm{DP}_{\mathrm{PI}}$, whereas the main impulse is due to the combined effect of DL and $\mathrm{DP}_{\mathrm{MI}}$ [Sastri et al., 2001]. Last, large-amplitude pulsations $\left(\mathrm{P}_{\mathrm{SC}}\right)$ occasionally appear at high latitudes after the $\mathrm{SC}$ occurrence.

[4] This basic paradigm has been successfully applied to a number of SC events [Araki, 1994]; however, more complex SSC manifestations have been reported in several cases [e.g., Araki et al., 1997; Sastri et al., 2001; Moiseyev et al., 2002]. In particular, at low latitudes $\left(\Lambda \approx 35^{\circ}\right)$, Kikuchi and Araki [1985] found that a "preliminary positive impulse" (PPI, with a timescale of less than $1 \mathrm{~min}$ and an average amplitude of $\approx 16 \mathrm{nT}$ ) often precedes the SCs both at morning and afternoon hours. Of the 10 events, 2 were associated with similar PPIs also at equatorial latitudes. The morning PPIs could be a result of the magnetic field decrease caused by the DP field superposed to the DL field [Tsunomura, 1998]; conversely, afternoon PPIs do not match with the DP current system. Kikuchi et al. [2001] analyzed 46 low-latitude PPIs and showed that afternoon PPIs occurred exclusively in the winter (suggesting that ionospheric conductivity plays an important role), while there was no significant seasonal dependence for morning PPIs. They also presented a case study in which the low-latitude PPI was associated with PRI near dip equator. After subtracting the expected DL, they proposed that the low-latitude PPI consisted of a "true" PPI and a succeeding negative impulse and interpreted the experimental observations in terms of a major role of the FAC in the magnetic field perturbations at low latitudes.

[5] A series of remarkable interplanetary events in April 2002 drew the attention of the space weather community and promoted integrated descriptions of the complex behavior of the coupled Sun-Earth system. With the present paper we intend to contribute to this joint scientific effort providing a detailed analysis of the highresolution measurements (1 s) performed at three stations of our low-latitude geomagnetic array, SEGMA (AQU, corrected geomagnetic latitude $\Lambda=36.3^{\circ}$; $\mathrm{RNC}, \Lambda=$ $38.2^{\circ}$; NCK, $\Lambda=42.7^{\circ} ;$ MLT $\approx \mathrm{UT}+1.30$, MLT being the magnetic local time [Vellante et al., 2002]) during the SC event occurred on 17 April 2002. We restricted our analysis to a small area in the noon quadrant focusing attention on the significant differences which appear at nearby stations during a $\approx 40 \mathrm{~min}$ interval characterized by a compression of the Earth magnetosphere and northward interplanetary magnetic field (IMF) conditions. For this scope we compared SEGMA observations with those
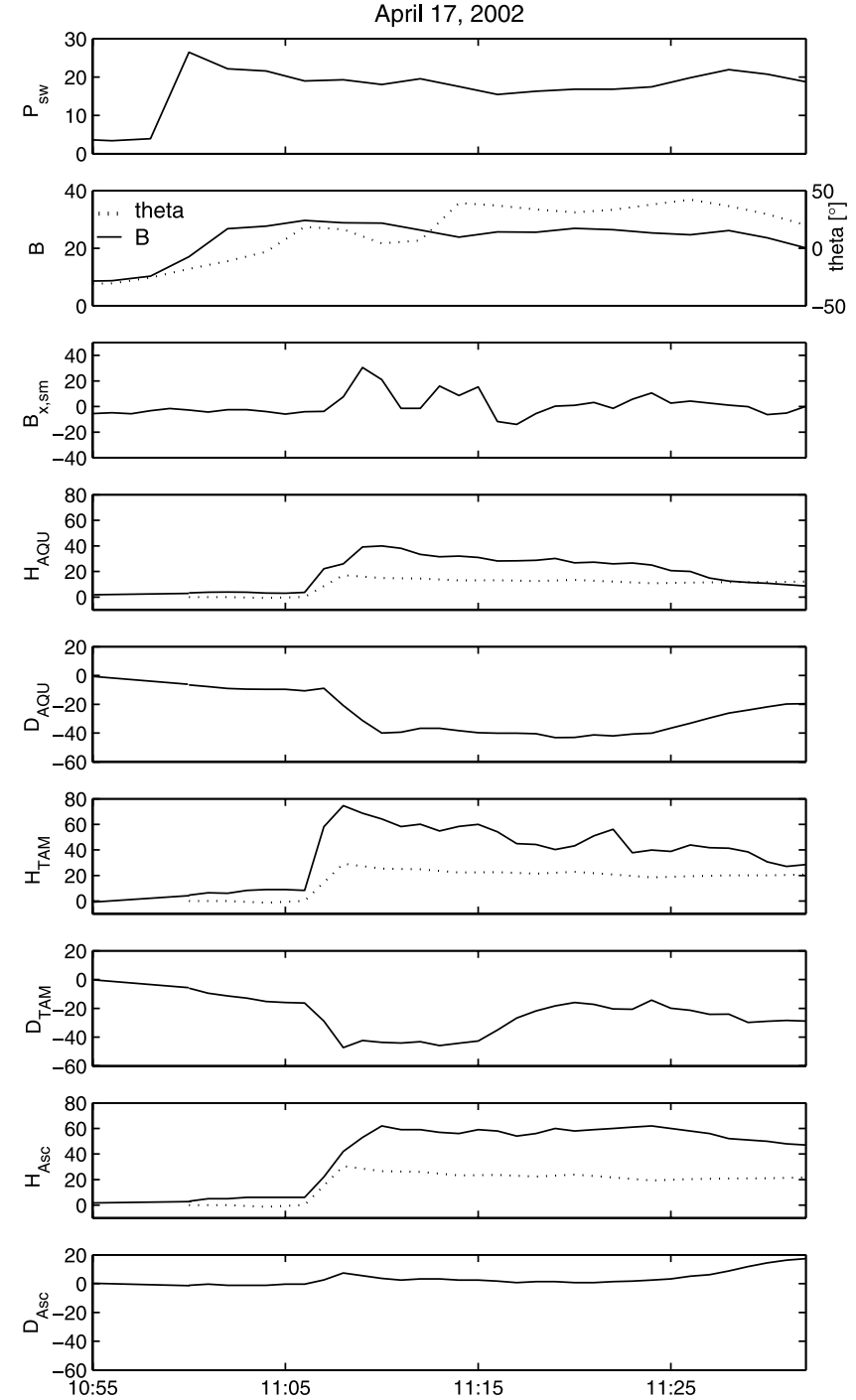

Figure 1. The solar wind (WIND), magnetospheric (Goes 8), and geomagnetic field observations (AQU, TAM, and ASC) for the SC event occurred on 17 April 2002. From the top: the $\mathrm{SW}$ dynamic pressure $\left(\mathrm{nT}^{\mathrm{n}} / \mathrm{nP}_{\mathrm{a}}^{1 / 2}\right)$; the IMF magnitude (nT) and inclination with respect to the ecliptic plane (dotted lines); the $\mathrm{B}_{\mathrm{x}, \mathrm{sm}}$ component at geostationary orbit (nT); the north-south $(\mathrm{H})$, the east-west (D) component of the geomagnetic field (nT). Dotted lines on the $\mathrm{H}$ plot identify the DL field model at AQU, TAM, and ASC (nT). DL field has been evaluated for an ellipsoidal magnetosphere in terms of the Chapman-Ferraro current and of the induced currents in the interior of the Earth [Tsyganenko, 1995, 1996, 2002a, 2002b].

obtained at SAMNET, IMAGE, and BGS stations (5 s), as well as with low-resolution measurements $(1 \mathrm{~min})$ at two equatorial stations, approximately in the same quadrant.

[6] The present analysis provides several interesting results. In particular, it reveals a significant contribution at low latitudes of the polar current system: it plays a different role for events with "morning" and "afternoon" characteristics, respectively, and explicitly determines their asymptotic response. We also identified additional aspects, which, 


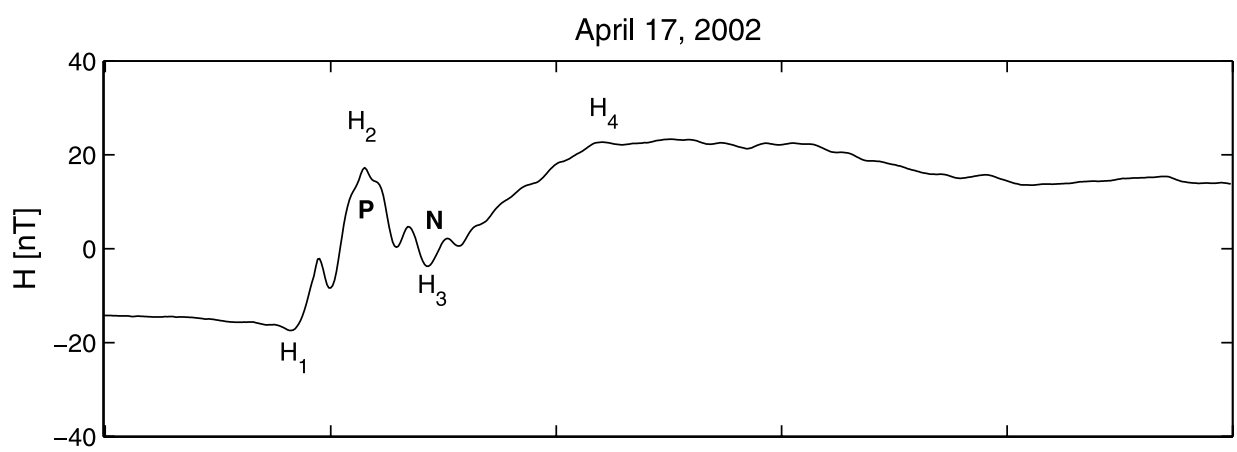

a)

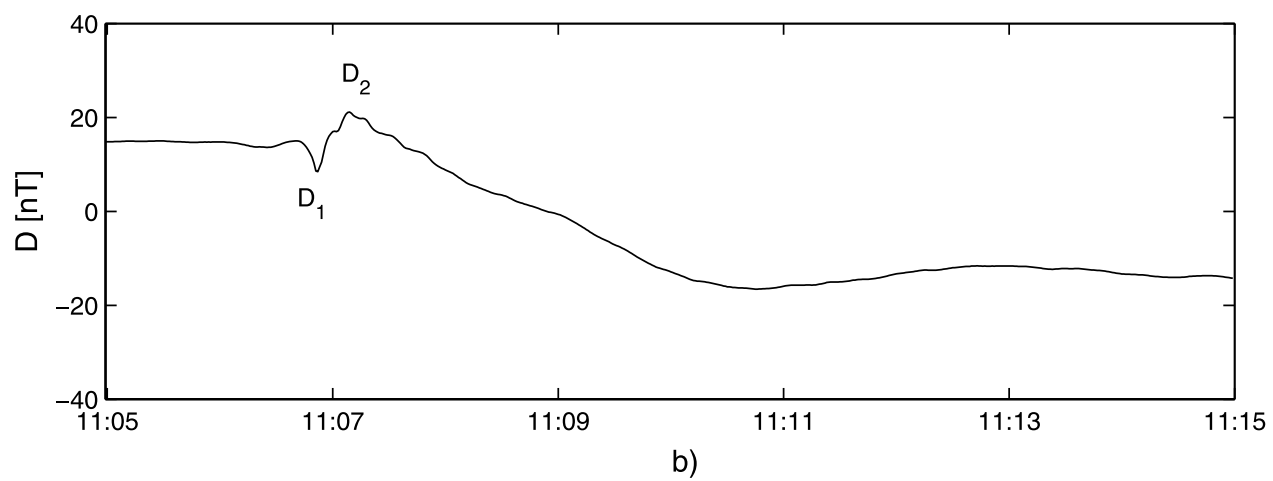

Figure 2. One-second measurements of the geomagnetic field components at AQU.

in our opinion, are important for a better understanding of the SC manifestation.

\section{Experimental Results}

\subsection{General Aspects of the Geomagnetic Response}

[7] As shown in Figure 1, an interplanetary shock was detected by Wind $\left(X_{S E} \approx 12.8 R_{E}, Y_{S E} \approx 200.8 R_{E}\right)$ on 17 April 2002 at $\approx 1100$ UT. The SW velocity, in less than $3 \mathrm{~min}$, varied from $\approx 330$ to $\approx 450 \mathrm{~km} / \mathrm{s}$ (with peak values of $\approx 520 \mathrm{~km} / \mathrm{s}$ ), the density varied from $\approx 20$ to $\approx 70 \mathrm{~cm}^{-3}$ and persisted high for approximately 2 hours; as a consequence, the dynamic pressure varied from $\approx 4$ to $\approx 23 \mathrm{nPa}$ (with peak values of $\approx 28 \mathrm{nPa}$ ). The IMF increased from $\approx 8$ to $\approx 26 \mathrm{nT}$; its orientation turned northward after the shock front and maintained this orientation up to $\approx 1150$ UT. At geostationary orbit, in the dawn sector (where the magnetospheric response is much less explicit than in the noon quadrant [Kokubun, 1983; Kuwashima and Fukunishi, 1985; Sastri et al., 2001]), Goes 8 detected an irregular SC variation, mostly on the $\mathrm{B}_{\mathrm{x}}$, sm component, at $\approx 1107-1110$ UT $(\approx 0602-0605$ MLT).

[8] Geomagnetic field measurements at low latitudes in the subsolar quadrant (AQU, $1 \mathrm{~min}$ averages in Figure 1) show, on the $\mathrm{H}$ component, an SC signature characterized by a double step increase (with a rise time of $\approx 3-4 \mathrm{~min}$, 1106-1110 UT), followed by a long-term decrease to a new steady state. As can be seen, the comparison with simple model predictions reveals that the variation of the $\mathrm{H}$ component is remarkably larger than expected for the DL contribution alone [Tsyganenko, 1995, 1996, 2002a, $2002 \mathrm{~b}$. Nevertheless, its peak variation $\left(\approx 10.6 \mathrm{nT} /(\mathrm{nPa})^{1 / 2}\right)$ is smaller than usually estimated $\left(13-14 \mathrm{nT} /(\mathrm{nPa})^{1 / 2}[\right.$ Siscoe et al., 1968; Su and Konradi, 1975; Nishida, 1978]). On the other hand, from the temporal variation of $\mathrm{P}_{\mathrm{sw}}$ we would expect a more prominent step-like change. The D component shows an explicit decrease, which is indicative of a long-lasting DP contribution [Tsunomura, 1998]. It is interesting to remark that this contribution is still significant at $\operatorname{TAM}\left(\Lambda=11.4^{\circ}, \operatorname{MLT}=\mathrm{UT}+0.56\right)$, while equatorial measurements (ASC, $\Lambda=2.1^{\circ}$, MLT $=$ UT - 0.37) do not show significant $D$ variation. Moreover, at TAM, the $\mathrm{H}$ variation is steeper, and mostly resembles the $\mathrm{P}_{\mathrm{sw}}$ behavior.

\subsection{High-Resolution Measurements}

[9] When examined on higher timescale (1 s), AQU measurements reveal a composite SC structure. Indeed, in the $\mathrm{H}$ component a negative variation $(\mathrm{N})$ is superimposed to the main positive variation $(\mathrm{P})$ soon after its onset (Figure 2a). Consequently, the $\mathrm{H}$ behavior is characterized by a preceding signal (with a peak value, $\mathrm{H}_{2}$, at 1107:20 UT), a main positive variation $\left(\mathrm{H}_{4}, 1110: 50 \mathrm{UT}\right)$, and then a long-term decrease. As a matter of fact, this behavior basically reflects that one proposed, at higher latitudes, by model predictions in the morning sector, with a positive then negative variation $(\mathrm{P} / \mathrm{N})$ preceding the main variation [Araki, 1994]. On the other hand, according to the criteria proposed by Kikuchi and Araki [1985], the preceding $\mathrm{H}$ structure may be identified as a PPI: it has a global duration of $\approx 70 \mathrm{~s}$, and peak amplitude of $\approx 34 \mathrm{nT}$ (i.e., larger than usually observed). It is also interesting to remark that, as for other events [Kikuchi et al., 2001], the lowlatitude PPI is anticipated by a small amplitude and a rapid decrease $\left(\mathrm{H}_{1}\right)$. Several fluctuations are superimposed to the basic pattern and suggest a complex PPI structure. This 
a) $\mathrm{H}$ - component

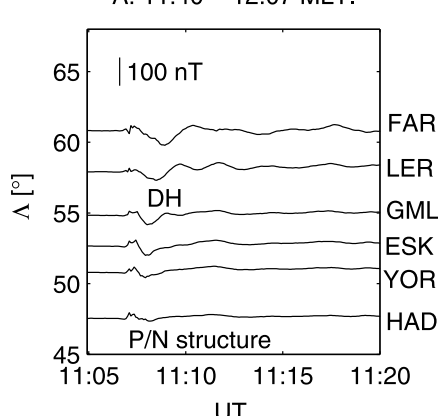

C: 13:05 - 13:16 MLT.

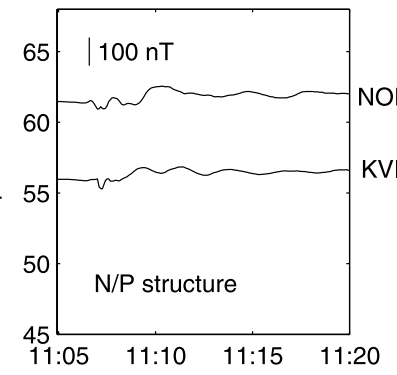

UT
D: 13:42 - 13:54 MLT.

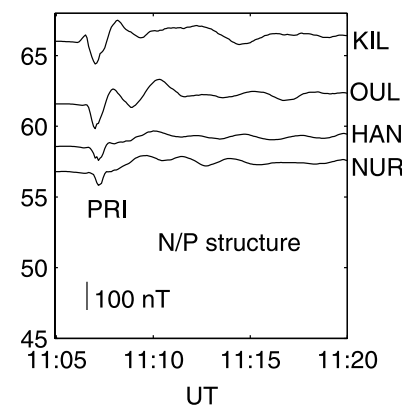

B: $12: 37-12 \cdot 54 \mathrm{MLT}$

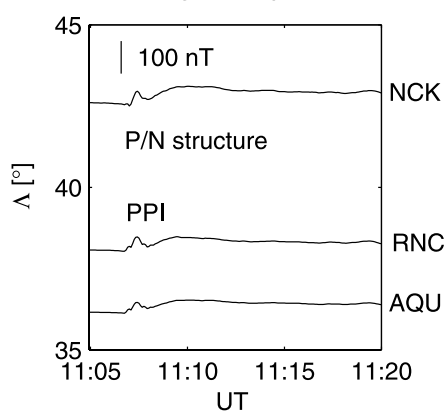

b) D - Component

A: 11:40 - 12:07 MLT.

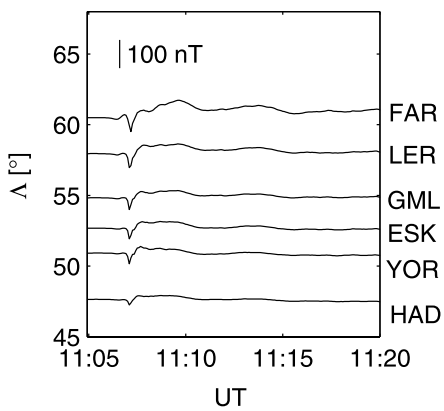

C: 13:05 - 13:16 MLT.

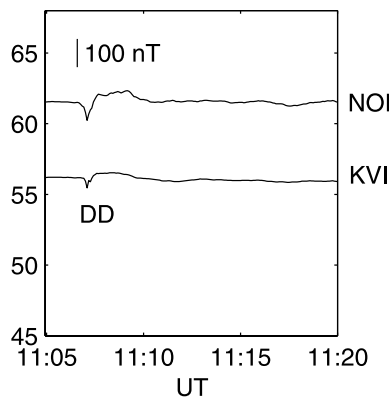

NOR

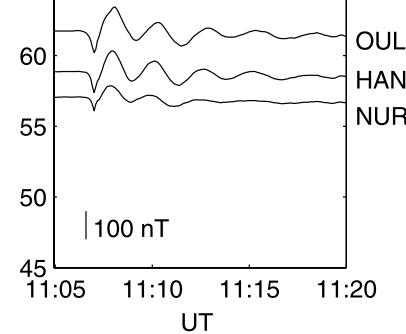

B: $12: 37$ - 12:54 MLT

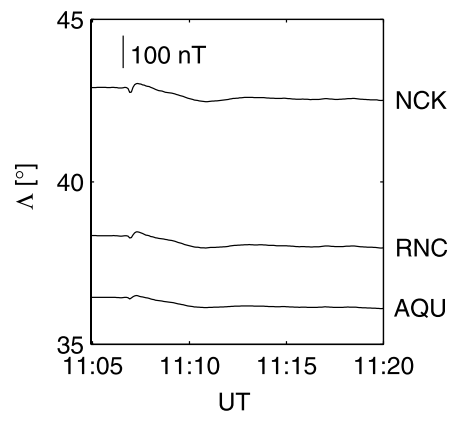

Figure 3. The geomagnetic field measurements at different stations, as organized in different MLT sectors. (a) H component; (b) D component.

feature is confirmed by the $\mathrm{D}$ component (Figure $2 \mathrm{~b}$ ), which exhibits an earlier $\mathrm{N} / \mathrm{P}$ structure $\left(\mathrm{D}_{1}, \mathrm{D}_{2}\right)$ with different duration times $(\approx 20 \mathrm{~s})$.

[10] Figure 3 shows the $5 \mathrm{~s}$ measurements at different stations, as organized in narrow ( $8-17$ min) MLT sectors in the subsolar region. SEGMA stations are located in the B sector: here the experimental observations, for the $\mathrm{H}$ com- ponent (Figure 3a), confirm the "morning" pattern (i.e., with a PPI preceding the main variation) at least up to $\Lambda \approx$ $43^{\circ}$ (NCK). Conversely, the $\mathrm{H}$ trace at KVI $\left(\Lambda \approx 56^{\circ}\right.$, $\mathrm{C}$ sector) might be better considered already indicative of a PRI preceding the main variation. At higher latitudes (NOR, $\Lambda \approx 61^{\circ}$ ) the irregular trace does not allow an unambiguous identification of the characteristics of the preliminary 
a)

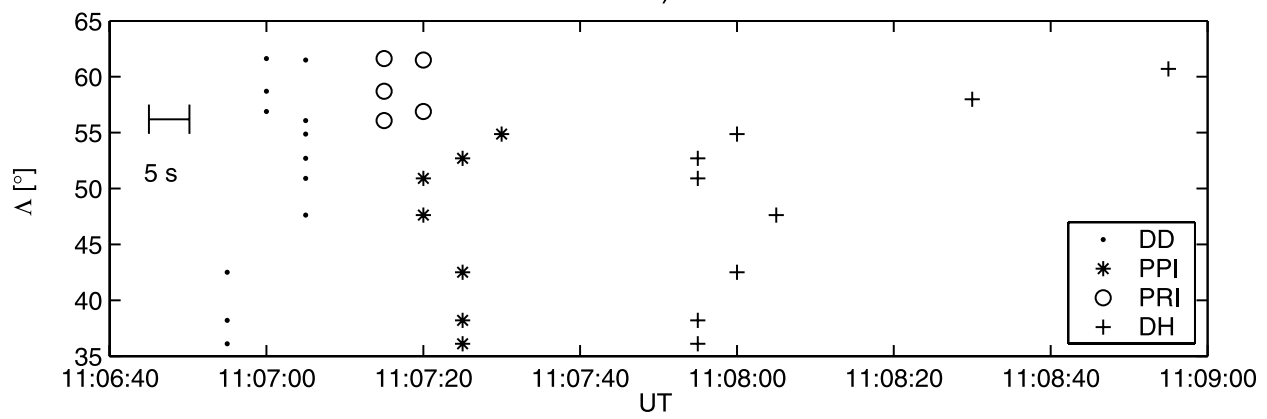

b)

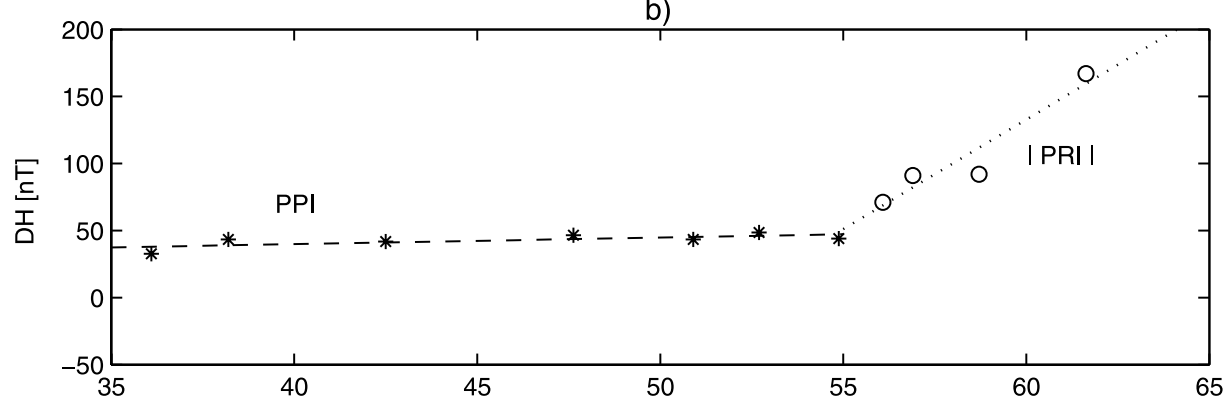

c)

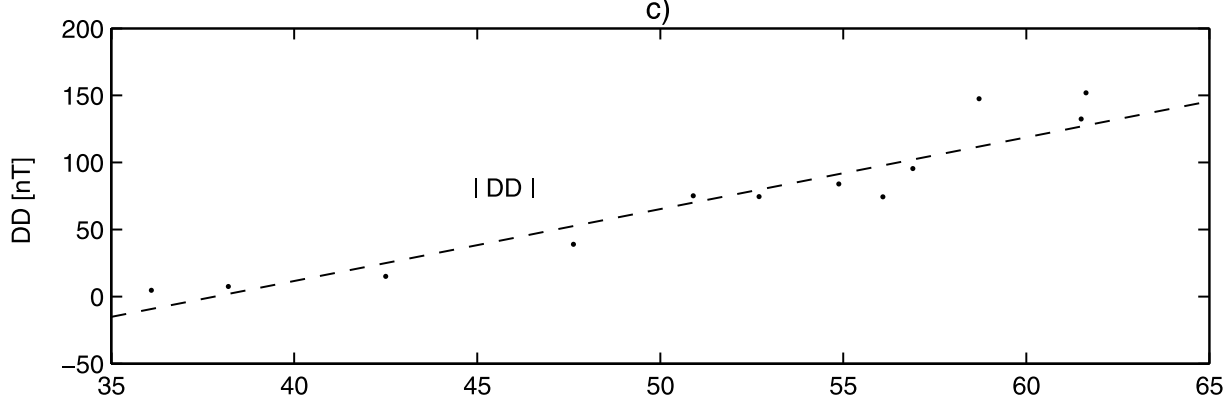

d)

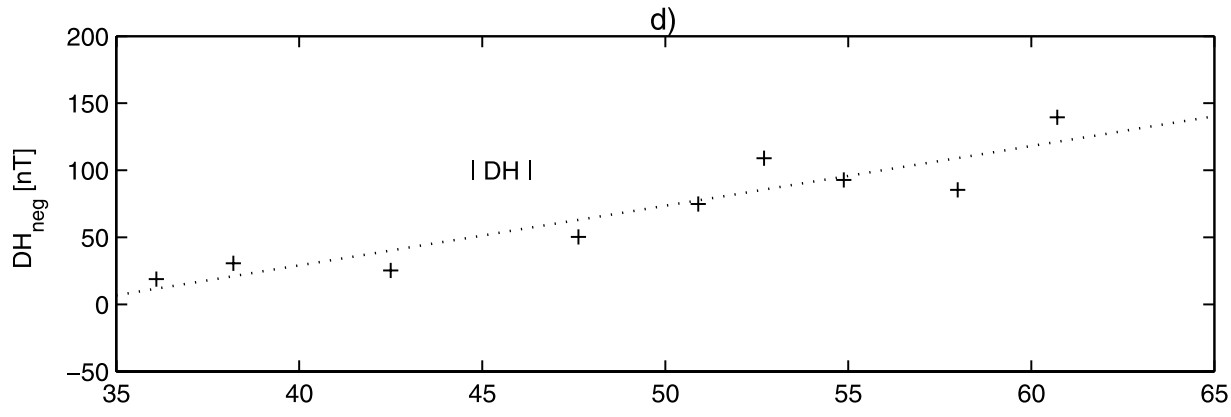

$\Lambda\left[^{\circ}\right]$

Figure 4. The principal characteristics of PPI, PRI, DD. (a) The time occurrence of PPI, PRI, DD, and negative variation (DH) following PPIs; (b) PPI and PRI amplitude as a function of geomagnetic latitude; (c) DD amplitude as a function of geomagnetic latitude; (d) DH amplitude as a function of geomagnetic latitude.

events. Approximately the same pattern detected at KVI, more explicit emerges at NUR $\left(\Lambda \approx 57^{\circ}\right)$ and HAN $\left(\Lambda \approx 59^{\circ}\right)$ in the $\mathrm{D}$ sector; a more complex structure appears at $\mathrm{KIL}\left(\Lambda \approx 66^{\circ}\right)$, where the negative variation is anticipated by a positive impulse of smaller amplitude. In agreement with the global scenario, in the earliest sector
(A), the basic pattern appears consistent with $\mathrm{P} / \mathrm{N}$ variation expected in the morning sector at least up to GML $(\Lambda \approx$ $55^{\circ}$ ); while at higher latitudes the $\mathrm{H}$ trace (still indicative of a preceding positive variation) becomes more irregular. Unfortunately, high-resolution measurements are not available at equatorial latitudes: so we cannot identify the 
a)

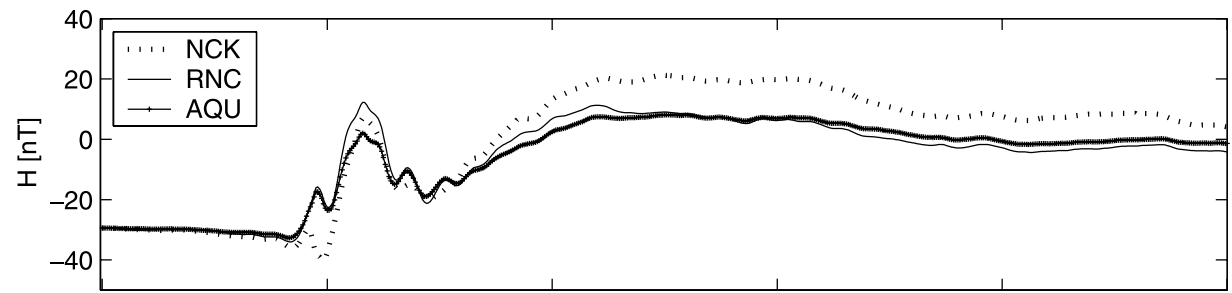

b)
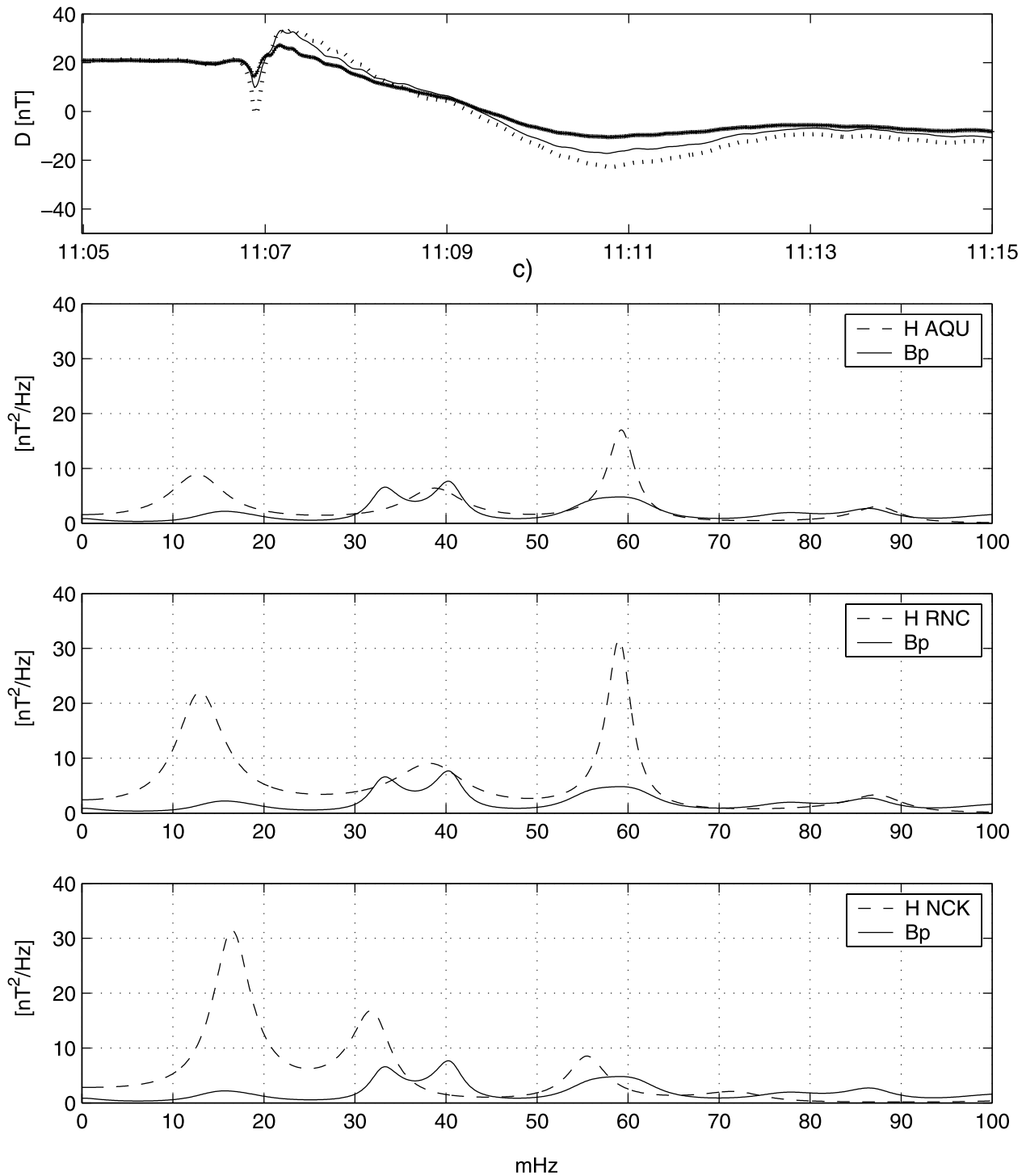

Figure 5. A comparison between $1 \mathrm{~s}$ measurements at SEGMA stations: (a) $\mathrm{H}$ component, (b) $\mathrm{D}$ component. (c) The power spectra of the H component at SEGMA stations (1105-1109 UT) compared with the power spectra of the $B_{p}$ component of the magnetospheric field (i.e., parallel to the Earth's rotation axis). The power spectra have been evaluated on differentiated data by means of the maximum entropy method.

possible occurrence either of a PPI or PRI, which is an important element for a better understanding of the SC manifestation [Araki, 1994; Kikuchi et al., 2001].

[11] The D component reveals its rapid N/P structure, with sharp minimum values (DD, Figure $3 b$ ) in each time sector. Moreover, in the subauroral region, in the D sector, its trace is characterized by large-amplitude fluctuations, which appear at the SC occurrence and persist for several cycles. These fluctuations are much less evident in other MLT sectors and at higher latitudes (as confirmed by visual 
inspection of data from other stations). A joint analysis of $\mathrm{H}$ and $\mathrm{D}$ measurements revealed almost regular fluctuations, with an approximate period $\mathrm{T} \approx 150-160 \mathrm{~s}$, and polarization axis at large angles with respect to $\mathrm{H}$ : this features conflicts with the resonance phenomena (often invoked to interpret the occurrence of similar events [Araki, 1994; Petrinec et al., 1996]) which would rather predict a polarization axis basically along $\mathrm{H}$.

[12] The results of Figure 3 also suggest the nonsimultaneous occurrence of PPIs and PRIs in different sectors and reveal that the negative variation $(\mathrm{DH})$ following PPIs becomes progressively deeper and longer with increasing latitude. These aspects are made clear in Figure 4, which reveals that "afternoon" PRIs occur approximately $0-10 \mathrm{~s}$ before "morning" PPIs. They are preceded by the DD structures, which at higher latitudes appear later than at lower latitudes. Moreover, the absolute amplitude of PRIs, DHs, and DDs explicitly increases with latitude (note that DH and DD show the same latitudinal variation), a feature that clearly reveals their high-latitude origin. In particular, their latitudinal trends would lead to predict vanishing amplitude of PRIs at $\approx 52^{\circ}$ and at $\approx 32^{\circ}$ for $\mathrm{DHs}$ and DDs. Conversely, the PPI amplitude reveals only a small increase between low and subauroral latitudes.

\subsection{An Analysis of PPI Structure at Low Latitudes}

[13] Kikuchi et al. [2001] investigated the PPI structure assuming that the step-like variation of the $\mathrm{H}$ component at very low latitudes $\left(\approx 14^{\circ}\right)$ was entirely caused by the DL field, and subtracting this signal from low-latitude measurements. The results of Figure 1 show that this technique cannot be used in the present case: indeed, the experimental observations are clearly indicative of a significant DP contribution at $\approx 11^{\circ}$.

[14] However, an analysis of $1 \mathrm{~s}$ measurements at SEGMA stations reveals interesting aspects. Figures $5 \mathrm{a}$ and $5 \mathrm{~b}$ show a superposition of geomagnetic field traces. As can be seen, at AQU and RNC the field traces closely follow each other. Conversely, significant modifications appear in the NCK trace. In particular, the initial superimposed fluctuations do not appear in phase with AQU/RNC traces; at NCK they depress $\mathrm{H}$ below pre-SC values and determine a peak to peak excursion $(\approx 47.2 \mathrm{nT})$ appreciably larger than at AQU $(\approx 34.7 \mathrm{nT})$. In addition, the results of Figure $5 \mathrm{a}$ show at NCK a more pronounced enhancement associated with the main variation.

[15] The different aspects of AQU/RNC and NCK observations are confirmed by the power spectra of differentiated $\mathrm{H}$ measurements as evaluated by means of the maximum entropy method. Figure 5c reveals that the PPI basically consists of different signals at well-defined frequencies. In particular, at AQU and RNC, it consists of common peaks in the $\mathrm{H}$ component (with different relative importance), at $\approx 12 \mathrm{mHz}, \approx 38 \mathrm{mHz}, \approx 59 \mathrm{mHz}$, and a less pronounced power enhancement at $\approx 87 \mathrm{mHz}$; conversely, at NCK, power peaks appear at $\approx 17 \mathrm{mHz} \approx 32 \mathrm{mHz}, \approx 56 \mathrm{mHz}$, $\approx 71 \mathrm{mHz}$. Power spectra of the D component (not shown) reveal a less clear situation with much lower energy content. As shown in Figure $5 \mathrm{c}$, broad power enhancements $(\approx 15 \mathrm{mHz}, \approx 33 \mathrm{mHz}, \approx 40 \mathrm{mHz}, \approx 59 \mathrm{mHz}, \approx 86 \mathrm{mHz})$ are observed also in the dawn sector in the $\mathrm{B}_{\mathrm{P}}$ component of the magnetospheric field (i.e., parallel to Earth's rotation axis). The different results detected in ground observations might be tentatively interpreted in terms of cavity-like oscillations [Yumoto, 1994], which couple with local field line resonance. In particular, the more prominent peak $(\approx 59 \mathrm{mHz})$ at lower-latitude stations is close to the expected local resonant frequency $(\approx 60 \mathrm{mHz})$; at the same time the local resonance at $\mathrm{NCK}(\approx 30 \mathrm{mHz})$ may well interpret the peak at $\approx 32 \mathrm{mHz}$.

\subsection{Asymptotic Response}

[16] The asymptotic response has been usually determined comparing pre-SC averages of the $\mathrm{H}$ component with those evaluated $\approx 10$ to $15 \mathrm{~min}$ after the peak values [Russell et al., 1992, 1994a, 1994b; Russell and Ginskey, 1995; Francia et al., 2001; Villante and Di Giuseppe, 2004]. Accordingly, in Figure 6a we show the results obtained by a simple difference, $\mathrm{DH}_{\mathrm{As}}$, between $10 \mathrm{~min}$ averages of the $\mathrm{H}$ component $\approx 20 \mathrm{~min}$ after the peak response (1130-1140 UT) and those obtained before the SC manifestation (1055-1105 UT). It is clear the appearance of two regimes with different $\mathrm{DH}_{\mathrm{AS}}$ (for comparable latitudes) and latitudinal trend. More particularly, "morning" events (i.e., associated with $\mathrm{P} / \mathrm{N}$ structure) show a gentle latitudinal decrease, with a coefficient $\mathrm{k}=-1.2 \mathrm{nT} /{ }^{\circ}$ (the transition between positive and negative $\mathrm{DH}_{\mathrm{AS}}$ occurs at $\approx 52^{\circ}$ ). Conversely, "afternoon" events (i.e., for $\mathrm{H}$ traces consistent with N/P structures) are clearly characterized by large negative $\mathrm{DH}_{\mathrm{AS}}$ (up to $\approx 70 \mathrm{nT}$ at $\approx 61.5^{\circ}$ ), together with a much steeper latitudinal decrease $\left(\mathrm{k}=-7.0 \mathrm{nT} /{ }^{\circ}\right)$. The $\mathrm{D}$ component also shows negative values (with an average value of $\approx-14 \pm 8 \mathrm{nT}$ ); however, it does not reveal any explicit latitudinal dependence (Figure 6b).

[17] In order to evaluate the whole asymptotic response, following Villante and Di Giuseppe [2004], we identified the direction (M1, positive for a northward and eastward orientation) of maximum variation of the global field. For this scope we evaluated, at steps of $1^{\circ}$, the total variation $\left(\mathrm{DB}_{\mathrm{AS}}\right)$ of the geomagnetic field between $10 \mathrm{~min}$ averages before and after the SC occurrence. Figure 6c shows the results obtained for the $\mathrm{DB}_{\mathrm{AS}}$ projection along $\mathrm{M} 1$ : in this case the gentler gradient corresponds to $\mathrm{k}=-1.8 \mathrm{nT} /{ }^{\circ}$, while the steeper gradient corresponds to $\mathrm{k}=-6.6 \mathrm{nT} /{ }^{\circ}$. As a matter of fact, if a horizontal current layer in the ionosphere generated the global field variations, the orientation of the equivalent current system could be inferred by a $90^{\circ}$ rotation of $\mathrm{M} 1$. As can be seen (Figure $6 \mathrm{~d}$ ), the emerging pattern reveals significant local deviations with respect to models and usual observations, in particular at lower latitudes, where current lines would be expected close to geomagnetic parallels [Nishida, 1968; Araki, 1994]. More particularly, the M1 axis shows approximately the same orientation at $\Lambda \approx 36^{\circ}$ and $\Lambda \approx 38^{\circ}$ (namely, $\Theta_{\mathrm{AQU}} \approx$ $48^{\circ}, \Theta_{\mathrm{RNC}} \approx 49^{\circ}, \Theta$ being the angle between $\mathrm{M} 1$ and $\mathrm{H}$ ), while it is oriented at larger $\Theta$ between $\Lambda \approx 43^{\circ}$ and $51^{\circ}$ $\left(\Theta_{\mathrm{NCK}} \approx 77^{\circ}, \Theta_{\mathrm{HAD}} \approx 74^{\circ}, \Theta_{\mathrm{YOR}} \approx 67^{\circ}\right)$ : it suggests a significant modification of the current system at $\approx 40^{\circ}$ in the subsolar sector.

\section{Summary and Discussion}

[18] In the present paper we investigated the complex manifestation of a SC event focusing attention on the different 
a)
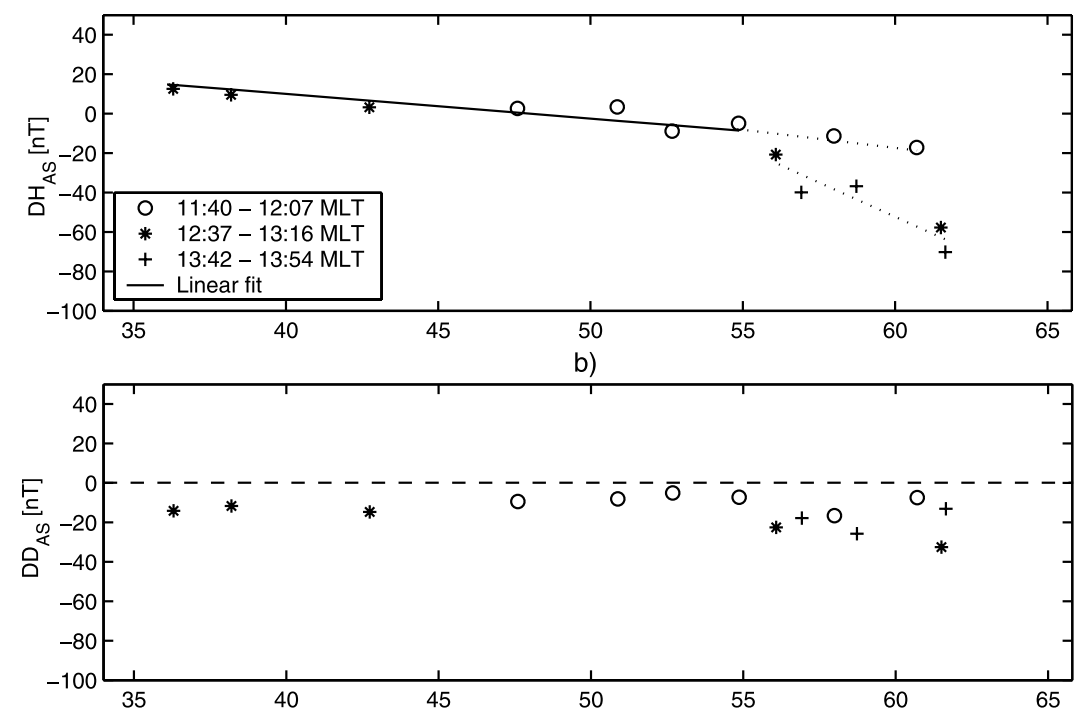

c)

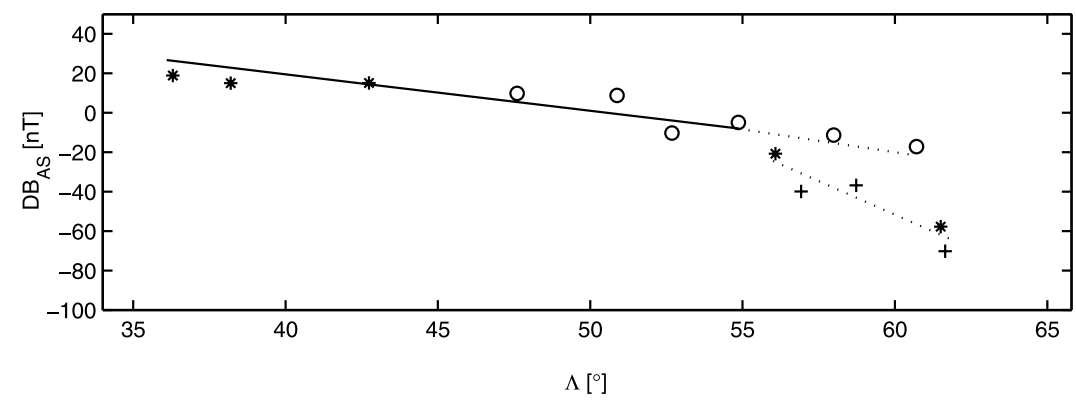

d)

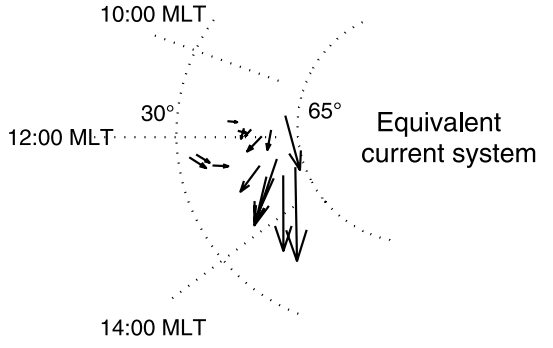

Figure 6. The asymptotic variation of the (a) H component, (b) D component, and total field DB along M1. (c) Different symbols identify different MLT sectors. Solid and dotted lines correspond to the linear least squares approximation of latitudinal decrease in different latitudinal ranges. (d) The equivalent current system.

aspects which emerge at low latitude in a $\approx 2$ hour interval in the subsolar sector. Main differences between nearby stations include the SSC structure, the asymptotic response, and the appearance of large-amplitude fluctuations.

[19] 1. The morphological differences in the SC manifestation suggest a boundary between $\mathrm{P} / \mathrm{N}$ and $\mathrm{N} / \mathrm{P}$ structures close to the 1300 MLT meridian. Above $\approx 60^{\circ}$ the SC manifestation becomes more irregular. Within the limits of the present investigation, this pattern can be considered consistent with the usual scenario detected at higher latitudes [Araki, 1994], where in the morning a positive pulse precedes and a negative pulse follows (with a consequent PPI) and the sense of the pulse is reversed in the afternoon (with a consequent PRI). This pattern is currently interpreted in terms of a superposition of the low-latitude DL field and the high-latitude DP field. Its extension to low latitudes is clearly supported in the present case by the clear manifestation of the DP field up to $\Lambda \approx 10^{\circ}$ and by the latitudinal variation of PRIs and DHs (and DDs). However, the clear tendency for higher-latitude PRIs to precede lowerlatitude PPIs, as well as the negligible latitudinal dependence of the PPI amplitude are important elements that should be considered for a better representation of the SC manifestation. The afternoon current system, moreover, in the subauroral region reveals large-amplitude fluctuations (rapidly decreasing with decreasing latitude), which cannot 
be interpreted in terms of local resonance phenomena [Araki, 1994; Petrinec et al., 1996]. Conversely, resonant phenomena may interpret the small-scale differences which emerge at low latitudes, where the PPI structure consists of three almost monochromatic signals with different relative amplitude.

[20] 2. Kikuchi et al. [2001] interpreted the seasonal dependence of the PPI/PRI occurrence during the day, suggesting the FAC effects overcome the ionospheric effects in winter while the opposite situation should occur in summer. As a consequence, PPIs should be observed in winter at afternoon midlatitudes, and PRIs should be observed in summer around noon and in the afternoon. As previously remarked, the present observations (and the lack of high-resolution measurements at equatorial latitudes) do not provide elements for a composite scenario: however, it is worth noting that FAC and ionospheric currents should approximately compensate at low latitudes around noon during spring months: then any prediction of possible PPI/PRI manifestations might be questionable. On the other hand, the D component reveals negative asymptotic variations at each station. In this sense it is interesting to remark that Tsunomura [1988], who evaluated the FAC effects on the ground variations, proposed for a spring event an explicit negative variation of the $\mathrm{D}$ component in a wide sector centered around noon from low to subauroral latitudes.

[21] 3. The asymptotic response of the $\mathrm{H}$ component is characterized by positive and negative values below and above $\Lambda \approx 52^{\circ}$. Moreover, it is strongly influenced by the shape of the $\mathrm{SC}$ manifestation $(\mathrm{N} / \mathrm{P}$ or $\mathrm{P} / \mathrm{N})$, and, for comparable latitudes, structures characterized by a N/P variation are associated with much larger negative variations. It suggests a significant long-lasting contribution, which remarkably depresses the highlatitude $\mathrm{H}$ component in the afternoonside. This is an important aspect, which should be taken into account before comparing results obtained for the different events and inferring the MLT and latitudinal dependence of the asymptotic response [Siscoe et al., 1968; Su and Konradi, 1975; Nishida, 1978; Russell et al., 1992, 1994a, 1994b; Araki, 1994; Russell and Ginskey, 1995; Francia et al., 2001; Villante and Di Giuseppe, 2004]. In particular, previous statistical analysis proposed strongly depressed values of the $\mathrm{H}$ component in the morning (0600-1000 MLT) and peak values in the afternoon (1400-1600 MLT) from low to subauroral latitudes [Francia et al., 1999, 2001; Russell and Ginskey, 1995]. Our results suggest for the present case a region of depressed (and even negative) field values which extends at least to the noon quadrant.

[22] Acknowledgments. This research activity is supported by MIUR and Consorzio Area di Ricerca in Astrogeofisica. The authors thank the SAMNET team for magnetometer data. SAMNET is a PPARC National Facility operated by Lancaster University. Data from the IMAGE stations (Kilpisjärvi, Hankasalmi, Oulujärvi, and Nurmijärvi) are provided courtesy of the Finnish Meteorological Institute, the University of Oulu, and the Geological Survey of Sweden. Lerwick, Hartland, Eskdalemuir, Ascension Island data is provided courtesy of the British Geological Survey. Tamanrasset and Bangui data are provided courtesy of the Bureau Central de Magnetisme Terrestre of France. The authors, also, are grateful to Howard Singer (NOAA Space Environment Center) who provided magnetic field data from Goes 8 spacecraft and Nikolai Tsyganenko (NASA/GSFC) for his kind and helpful contribution.
[23] Arthur Richmond thanks Tohru Araki and J. Hanumath Sastri for their assistance in evaluating this paper.

\section{References}

Araki, T. (1977), Global structure of geomagnetic sudden commencements, Planet. Space Sci., 25, 372.

Araki, T. (1994), A physical model of the geomagnetic sudden commencement, in Solar Wind Sources of Magnetospheric Ultra-Low-Frequency Waves, Geophys. Monogr. Ser., vol. 81, edited by M. Engebretson, K. Takahashi, and M. Scholer, p. 183, AGU, Washington, D. C.

Araki, T., et al. (1997), Anomalous sudden commencement on March 24, 1991, J. Geophys. Res., 102, 14,075.

Francia, P., S. Lepidi, U. Villante, P. Di Giuseppe, and A. J. Lazarus (1999), Geomagnetic response at low latitude to continuous solar wind pressure variations during northward interplanetary magnetic field, J. Geophys. Res., 104, 19,923.

Francia, P., S. Lepidi, U. Villante, and P. Di Giuseppe (2001), Geomagnetic sudden impulses at low latitude during northward interplanetary magnetic field conditions, J. Geophys. Res., 106, 21,231.

Kikuchi, T., and T. Araki (1985), Preliminary positive impulse of geomagnetic sudden commencement observed at dayside middle and low latitudes, J. Geophys. Res., 90, 12,195.

Kikuchi, T., S. Tsunomura, K. Hashimoto, and K. Nozaki (2001), Field aligned current effects on mid-latitude geomagnetic sudden commencements, J. Geophys. Res., 106, 15,555.

Kokubun, S. (1983), Characteristics of storm sudden commencement at geostationary orbit, J. Geophys. Res., 88, 10,025.

Kuwashima, M., and H. Fukunishi (1985), Local time asymmetries of the SSC-associated hydromagnetic variations at geosynchronous altitude, Mem. Natl. Inst. Polar Res., 36, 136.

Matsushita, S. (1962), On geomagnetic sudden commencements, sudden impulses, and storm duration, J. Geophys. Res., 67, 3753.

Moiseyev, A. V., S. I. Solovyev, and K. Yumoto (2002), Relation between the formation of preliminary and main SI impulses during a sharp compression of the magnetosphere by solar wind, paper presented at 25th Annual Seminar on Physics of Auroral Phenomena, Russian Acad. of Sci., Apatity, Russia.

Nishida, A. (1968), Geomagnetic DP2 fluctuations and associated magnetospheric phenomena, J. Geophys. Res., 73, 1795.

Nishida, A. (1978), Geomagnetic Diagnosis of the Magnetosphere, Springer, New York

Nishida, A., and A. J. Jacobs (1962), World wide changes in geomagnetic field, J. Geophys. Res., 67, 525

Petrinec, S. M., K. Yumoto, H. Lühr, D. Orr, D. Milling, H. Hayashi, S. Kokubun, and T. Araki (1996), The CME event of February 21, 1994: Response of magnetic field at Earth's surface, J. Geomagn. Geoelectr., 48, 1341

Russell, C. T., and M. Ginskey (1995), Sudden impulses at subauroral latitudes: Response for Northward interplanetary magnetic field, J. Geophys. Res., 100, 23,695.

Russell, C. T., M. Ginskey, S. Petrinec, and G. Le (1992), The effect of solar wind dynamic pressure changes on low and mid-latitude magnetic records, Geophys. Res. Lett., 19, 1227.

Russell, C. T., M. Ginskey, and S. Petrinec (1994a), Sudden impulses at low-latitude stations: Steady state response for Northward interplanetary magnetic fields, J. Geophys. Res., 99, 253.

Russell, C. T., M. Ginskey, and S. Petrinec (1994b), Sudden impulses at low-latitude stations: Steady state response for Southward interplanetary magnetic fields, J. Geophys. Res., 99, 13,403.

Sastri, J. H., T. Takeuchi, T. Araki, K. Yumoto, and S. Tsunomura (2001), Preliminary impulse of the geomagnetic storm sudden commencement of November 18, 1993, J. Geophys. Res., 106, 3905.

Siscoe, G. L., L. Davis, P. J. Coleman, E. J. Smith, and D. E. Jones (1968), Power spectra and discontinuities of the interplanetary magnetic field. Mariner 4, J. Geophys. Res., 73, 61.

Su, S. Y., and A. Konradi (1975), Magnetic field depression at the Earth's surface calculated from the relationship between the size of the magnetosphere and Dst values, J. Geophys. Res., 80, 195.

Tsunomura, S. (1998), Characteristics of geomagnetic sudden commencement observed in middle and low latitudes, Earth Planets Space Phys., 50,755 .

Tsyganenko, N. A. (1995), Modeling the Earth's magnetospheric magnetic field confined within a realistic magnetopause, J. Geophys. Res., 100, 5599.

Tsyganenko, N. A. (1996), Effects of the solar wind conditions on the global magnetospheric configuration as deduced from data-based field models, in Proceedings of the ICS-3 Conference on Substorms, Spec. Publ. SP-389, p. 181, Eur. Space Agency, Paris.

Tsyganenko, N. A. (2002a), A model of the near magnetosphere with a dawn-dusk asymmetry: 1. Mathematical structure, J. Geophys. Res., 107(A8), 1179, doi:10.1029/2001JA000219. 
Tsyganenko, N. A. (2002b), A model of the near magnetosphere with a dawn-dusk asymmetry: 2. Parameterization and fitting to observations, J. Geophys. Res., 107(A8), 1176, doi:10.1029/2001JA000220.

Vellante, M., M. De Lauretis, U. Villante, N. Adorante, A. Piancatelli, K. Schwingenschuh, W. Magnes, W. Koren, and T. L. Zhang (2002), A new meridional magnetometer array in middle-south Europe for monitoring dynamic processes in the coupled system plasmasphereionosphere, in SOLSPA 2001: Proceedings of the Second Solar Cycle and Space Weather Euroconference, Spec. Publ., SP-477, p. 487, Eur. Space Agency, Paris.

Villante, U., and P. Di Giuseppe (2004), Some aspects of geomagnetic response to solar wind pressure variations: A case study at low and middle latitudes, Ann. Geophys., 22, 2053.
Yumoto, K. (1994), Cavity-like and field-line oscillations of Pc 3-4 stimulated by interplanetary impulses, in Solar Wind Sources of Magnetospheric Ultra-Low-Frequency Waves, Geophys. Monogr. Ser., vol. 81, edited by M. Engebretson, K. Takahashi, and M. Scholer, pp. 335, AGU, Washington, D. C.

P. Di Giuseppe, M. Piersanti, M. Vellante, and U. Villante, Dipartimento di Fisica, Università ed Area di Astrogeofisica, Piazza dell'Annunziata, 1, L'Aquila, I-67100, Italy. (umberto.villante@aquila.infn.it)

W. Magnes and T. L. Zhang, Space Research Institute, Austrian Academy of Science, Graz, Austria. 